\title{
Repetitive TMS in treatment of resistant diabetic neuropathic pain
}

\author{
Ann A. Abdelkader', Amira M. El Gohary', Husam S. Mourad ${ }^{2 *}$ (D) and Dina A. El Salmawy ${ }^{1}$
}

\begin{abstract}
Background: Diabetes mellitus is a clinical syndrome characterized by hyperglycemia caused by respective or absolute deficiency of insulin. Painful neuropathy in diabetic population is popular, impacting numerous chronic diabetic patients. Although antidepressants, anticonvulsants, and opioid agonists are useful in alleviating painful neuropathy, they produce a diversity of side effects and are occasionally ineffective. Hence, there is presently a need to pursue safe, non-invasive, and effective therapeutic opportunities. Repetitive transcranial magnetic stimulation (rTMS) is a non-invasive mechanism used in releasing neuropathic pain. TMS pulses—when applied repetitively — can modulate cortical plasticity, consequently causing excitability or inhibition according to the rate of stimulation.
\end{abstract}

Objectives: The aim of this study is to evaluate the efficacy of repetitive transcranial magnetic stimulation (rTMS) in improving resistant chronic diabetic neuropathic pain.

Subjects and methods: Twenty patients were recruited and divided equally into two groups: insulin-dependent (group A) and non-insulin-dependent (group B). A high-frequency $(10 \mathrm{~Hz})$ rTMS stimulation protocol was applied to both groups for five consecutive days over lower limbs motor cortex. VAS score and nerve conduction studies were compared before and after rTMS sessions.

Results: Highly significant improvements in VAS and nerve conduction studies $(p>0.01)$ were detected for both patient cohorts following the administration of the rTMS protocol.

Conclusion: According to our study, rTMS significantly reduced painful diabetic neuropathy. rTMS may produce its analgesic effects, inducing motor cortex plasticity and activating descending inhibitory pain control systems.

Keywords: High-frequency repetitive transcranial magnetic stimulation, Painful diabetic neuropathy, Motor cortex, Nerve conduction

\section{Introduction}

Diabetes mellitus (DM) is a chronic and serious disorder with a far-reaching and devastating impact on overall global health. The incidence of DM has increased almost fourfold from 1980; the estimated number of individuals with this metabolic disease in 2014 was 420 million $[1,2]$. This DM epidemic is a consequence of population growth, urbanization, and increased prevalence of obesity and sedentary lifestyles [3].

$\mathrm{DM}$ is complex and heterogeneous in nature, and patients with uncontrolled disease are vulnerable to a multitude of microvascular and macrovascular complications

\footnotetext{
* Correspondence: husamneuro@kasralainy.edu.eg

${ }^{2}$ Department of Neurology, Kasr Al-Ainy Hospital, Cairo University, Cairo

12311, Egypt

Full list of author information is available at the end of the article
}

$[4,5]$. Diabetic neuropathies, a prevailing chronic complication of DM, are affecting over $90 \%$ of diabetic patients [6]. Defined by the presence of signs and/or symptoms of peripheral nerve dysfunction in diabetics, this sequela of DM can frequently lead to diabetic neuropathic pain, foot ulceration, and-potentially-limb amputations $[7,8]$.

Patients with diabetic neuropathic pain describe a tingling, burning, sharp, and shooting or an electric shock sensation that is prevalent at night. Such pain can impact patients' quality of life through sleep disturbances and/or an inability to carry out daily activities. Patients with painful neuropathies may develop depression because of pain-induced social and recreational withdrawal [6].

Diabetic neuropathic pain persists as a major therapeutic challenge to this day. Based on clinical trial observations, the American Diabetes Association (ADA) currently 
recommends treatment with a variety of mono- and poly-therapies that include anticonvulsants, antidepressants, and opioid agonists. These treatments however can often be ineffective, have a delayed onset of action, and produce undesirable side effects that add to the pre-existing burden of disease [9]. Despite advancements in elucidating mechanisms involved in neuropathic pain, only a few treatments targeting these mechanisms are available and evidence from randomized clinical trials remains limited [10].

The clinical effectiveness of neurostimulation to treat drug-resistant neuropathic pain has previously been demonstrated [11, 12]. Such techniques include invasive deep brain stimulation (DBS) and epidural motor cortex stimulation (MCS), both of which produce analgesic effects in patients reporting chronic pain [13]. Based on clinical findings for DBS and MCS, repetitive transcranial magnetic stimulation (rTMS) has recently emerged as a successor and non-invasive alternative for the management of chronic pain. rTMS induces changes in cortical excitability at the site of stimulation, leading to either facilitation or inhibition depending on the delivered frequency of the pulses. High-frequency $(>5 \mathrm{~Hz})$ rTMS enhances motor cortex excitability [14]. While the mechanisms underlying the stimulatory and inhibitory effects are unclear, it is widely believed to reflect changes in synaptic efficacy to long-term potentiation (LTP) and long-term depression (LTD) [15].

Onetsi and colleagues have recently reported that consecutive sessions of rTMS to the lower limb cortex produced analgesic effects in patients with diabetic neuropathy [16]. The primary objective of our investigation was to assess the clinical efficacy of rTMS for the management of chronic treatment-resistant neuropathic pain in an Egyptian diabetic cohort.

\section{Materials and methods}

This prospective, cross-sectional, single-center study was performed at the Kasr Al-Ainy Hospital diabetic outpatient and neurology outpatient clinics, Cairo University, Egypt. Twenty patients with chronic diabetic polyneuropathic drug-resistant pain for at least 1 year were recruited-including ten insulin-dependent and ten non-insulin-dependent patients. All subjects included in this investigation were between the ages of 18 and 60 years and had a written consent. Inclusion criteria were as follows: (1) patients with laboratory-confirmed diabetes for at least 10 years, (2) suffering from chronic symmetrical distal sensory polyneuropathy according to signs and symptoms, (3) patients experiencing chronic pain for at least 1 year with a Dyck severity score $\geq 2$ and a VAS score of 4 or higher, (4) resistance to medical therapies with proven effectiveness when administered as per the American Academy of Neurology Guidelines [17], and (5) patients with sensorimotor polyneuropathy for upper and/or lower limbs as determined by nerve conduction studies (NCS). Patients were excluded if they were pregnant and epileptic (or with a family history of epilepsy); had a pacemaker, intracranial metal objects, or metal tooth replacements; had other types of diabetic neuropathy (e.g., autonomic and/or focal neuropathies); experienced focal or systemic disorders that could otherwise explain their pain; and had a history of central nervous system or spinal disorders.

All participating patients-including both insulin- and non-insulin-dependent diabetics $(n=20)$-were subjected to a comprehensive clinical assessment which included physical and neurological examinations. Medical histories were recorded for all patients. A diagnosis of peripheral neuropathy was based on both clinical and electrodiagnostic findings-in adherence to the criteria proposed by the AAN. When diagnosing neuropathic pain, we utilized the diagnostic questionnaire DN4 to assess several pain characteristics. The subjective intensity of pain was assessed using VAS. Patients meeting all study inclusion and exclusion criteria received a high-frequency stimulation protocol for five consecutive days.

Neuropathic pain was assessed by means of a DN4 diagnostic questionnaire. This questionnaire was provided to patients prior to the treatment sessions and consisted of ten items that describe different pain characteristics [18, 19]. A score of at least $4 / 10$ possible points was considered acceptable to identify neuropathic pain with $83 \%$ sensitivity and $90 \%$ specificity. This questionnaire allows for an assessment of the pain character and also requires the examining physician to assess whether there is reduced sensation (hypoesthesia) to touch or pinprick and whether light brushing increases or causes pain (allodynia).

The subjective intensity of painful sensations was assessed with a ten-step VAS for pain prior to and following the treatment procedure. The VAS used in this study, and validated for both adults and children over 5 years of age, consists of a $10-\mathrm{cm}$ line, either vertical or horizontal, anchored at the ends by labels with a minimum score of 0 (no pain) and a maximum score of 10 (worst possible pain). Patients estimated the level of perceived pain sensation by marking the ten-step VAS [20, 21]. Any analgesic effects of rTMS were evaluated 3 weeks following the stimulation protocol.

All enrolled patients $(n=20)$ underwent NCS testing; motor functions of the ulnar, peroneal, and tibial nerves and the sensory functions of the ulnar and sural nerves were investigated. NCS testing was performed using $\mathrm{Ni}$ hon Kohden Neuropak M1 MEB-9200 EMG surface electrodes (Nihon Kohden Corporation, Tokyo, Japan) with the standard placement.

Our classification of polyneuropathy was concordant with the recommendations of the European Standardized Telematic tool to Evaluate Electrodiagnostic Methods 
(ESTEEM) group [22]. Two sensory or motor nerves with axonal loss in more than two extremities were required to diagnose axonal neuropathy. A diagnosis of demyelinating neuropathy was confirmed if one of the following criteria was met: (1) two nerves with definite demyelination in more than two extremities, (2) one nerve with definite demyelination and two with probable demyelination in more than two extremities, and (3) four nerves with probable demyelination in more than two extremities. Both criteria were needed to diagnose mixed neuropathy.

All enrolled patients $(n=20)$ received five consecutive sessions of high-frequency rTMS. We used a high-frequency repetitive transcranial magnetic stimulator (MagStim Rapid 2 magnetic stimulator, Magstim Company, Whitland, Wales and UK), connected with a figure-of-eight coil with a diameter of $70 \mathrm{~mm}$. The figure-of-eight coil was applied tangentially over the motor cortex of the lower limbs which was localized on the scalp at $\mathrm{Cz}$ (hot point of tibialis anterior muscle), with its handle pointing and positioned at the vertex, mid-sagittal of the head. Each session lasted a total of 40 min during which 15 consecutive trains ( $2 \mathrm{~s}$ duration) of 50 stimuli were delivered at $10 \mathrm{~Hz}$, at $100 \%$ motor threshold (MT), separated by intertrain intervals lasting $30 \mathrm{~s}$ [16].

\section{Statistical analysis}

Data was coded and entered using the statistical package for the social sciences (SPSS, version 23; SPSS Inc., Chicago, IL, USA). Quantitative data was summarized using mean, standard deviation, median, minimum, and maximum. Qualitative data was reported in terms of absolute frequency (number of cases) and relative frequency (percentages). Comparisons between groups were analyzed by means of the non-parametric Mann-Whitney test. The non-parametric Wilcoxon signed-rank test was employed when analyzing comparisons between variables measured prior to and following treatment administration [23]. Comparisons for categorical data were analyzed using the chi-square $(\chi 2)$ test. Exact test was alternatively used when the expected frequency was less than five. Correlations between quantitative variables were deduced using Spearman's correlation coefficients. $p$ values less than 0.05 were considered as statistically significant.

\section{Results}

A total of 20 participants were enrolled in our investigation. A summary of participant demographics is depicted in Table 1. Eleven female and nine male patients with chronic diabetic polyneuropathic drug-resistant pain were recruited. Enrollees included ten insulin-dependent diabetics (group A) including six females and ten non-insulin-dependent diabetics (group B) with an equal gender distribution. Both patient cohorts were statistically similar at baseline; the mean age was $52.1 \pm 6.45$ years and $57.9 \pm 10.22$ years, respectively $(p=0.211)$. The
Table 1 Participants' baseline characteristics

\begin{tabular}{|c|c|c|c|}
\hline Characteristic & $\begin{array}{l}\text { Group } A(N= \\
10)\end{array}$ & $\begin{array}{l}\text { Group } B(N= \\
10)\end{array}$ & $p$ \\
\hline \multicolumn{4}{|l|}{ Demographics } \\
\hline Women, no. (\%) & $6(60 \%)$ & $5(50 \%)$ & 1 \\
\hline Age, mean (range), y & $52.1(44-65)$ & $57.9(42-72)$ & 0.211 \\
\hline \multicolumn{4}{|l|}{ Disease characteristics } \\
\hline $\begin{array}{l}\text { Diabetes duration, mean } \\
\text { (SD), y }\end{array}$ & $13.10(3.21)$ & $12.80(3.36)$ & 0.697 \\
\hline DN4 score, mean (SD) & $6.60(0.84)$ & $6.50(0.97)$ & 0.87 \\
\hline VAS score, mean (SD) & $8.90(1.10)$ & $8.20(1.48)$ & 0.293 \\
\hline
\end{tabular}

DN4 Douleur Neuropathique 4, $p$ probability, SD standard deviation, VAS visual analogue scale, $y$ year

mean duration of diabetes was $13.1 \pm 3.21$ years for the insulin-dependent cohort and $12.8 \pm 3.36$ years for the non-insulin-dependent group $(p=0.697)$.

All patients in both cohorts were examined for peripheral neuropathic pain using the DN4 clinical examination scale. At baseline, both patient cohorts were statistically similar in regards to mean DN4 score (Table 1); the insulin-dependent and non-insulin-dependent cohorts reported scores of $6.60 \pm 0.84$ and $6.50 \pm 0.97$, respectively $(p=0.87)$. Similarly, no statistically significant differences in reported VAS scores were observed $(8.90 \pm 1.10 \mathrm{~mm}$ vs. $8.20 \pm 1.48 \mathrm{~mm} ; p=0.293$ ).

Patients in both cohorts were subjected to five consecutive rTMS sessions. VAS scores were measured 3 weeks following the end of treatment (Fig. 1). A significant reduction in mean VAS was observed for both insulin-dependent $\quad(5.10 \pm 2.6 \mathrm{~mm} ; p=0.011)$ and non-insulin-dependent $(4.0 \pm 1.7 \mathrm{~mm} ; p=0.005)$ patients. Post-treatment VAS scores for the two cohorts were statistically similar $(p=0.265)$.

Patients in both cohorts received a comprehensive peripheral neurophysiological examination which included NCS testing for both motor (tibial and ulnar) and sensory nerves (superficial peroneal, sural, and ulnar). Latencies, amplitudes, and conduction velocities for the aforementioned nerves and F-waves for both upper and lower limbs were assessed prior to and following treatment (Table 2). At baseline, both right and left ulnar sensory latencies were significantly higher in the insulin-dependent cohort $(p<0.05)$. Conversely, right ulnar sensory conduction velocity was significantly lower in the insulin-dependent cohort $(p<0.05)$. Following treatment, no statistically significant differences between the two cohorts were noted apart from right ulnar sensory nerve conduction velocity which was lower in the insulin-dependent diabetic cohort $(p<0.05)$.

Changes in nerve conduction parameters following treatment were also assessed for each cohort (Table 3). The insulin-dependent cohort exhibited significant 


\section{- Pre-treatment VAS $\quad$ Post-treatment VAS}
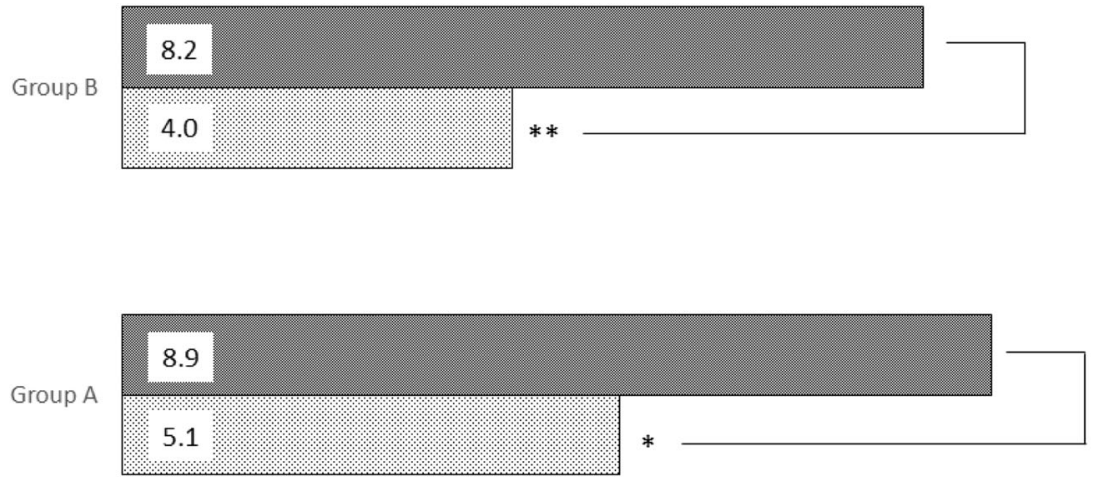

$* p<0.05$
$* * p<0.01$

\section{0}

2

4

6

8

10

Fig. 1 Pre- and post-treatment VAS score for insulin-dependent (group A) and non-insulin-dependent patients (group B)

improvements in latency for the right tibial nerve $(p=$ $0.035)$, peroneal nerve $(p=0.028$; Fig. 2$)$, left ulnar nerve $(p$ $=0.028)$, right ulnar sensory nerve $(p=0.012)$, left ulnar sensory nerve $(p=0.042)$, upper limb F-wave $(0.034)$, and lower limb F-wave $(p=0.043)$. Furthermore, significant increases in amplitude were noted for the left tibial nerve $(p$ $=0.007)$ and left ulnar sensory nerve $(p=0.043)$. Post-treatment increases in conduction velocity were observed for the right tibial nerve $(p=0.005)$, left tibial nerve $(p=0.028)$, peroneal nerve $(p=0.008$; Fig. 2$)$, right ulnar nerve $(p=0.005)$, right ulnar sensory nerve $(p=0.012)$, and left ulnar sensory nerve $(p=0.043)$, while sural latency, amplitude, and conductions showed no significant difference post-treatment. The non-insulin-dependent cohort on the other hand exhibited significant latency reductions for the following nerves: right tibial $(p=0.02)$, right ulnar $(p=$ $0.007)$, left ulnar $(p=0.007)$, left sensory ulnar $(p=0.027)$, and lower limb F-wave $(p=0.018)$. Significant increases in left ulnar amplitudes $(p=0.047)$ as well as increases in conduction velocities for the left tibial $(p=0.005)$ and peroneal $(p=0.074)$ nerves were also noted, while both sural and right ulnar sensory latencies, amplitudes, and conductions showed no significant difference post-treatment.

Potential correlations between the response to rTMS treatment, as evaluated by VAS, and baseline variables including age and disease duration were examined (Table 4). No statistically significant correlations between rTMS treatment response and age were observed $(r=0.76 ; p=0.75)$. Furthermore, no significant correlations with the duration of diabetes were identified $(r=-0.232 ; p=0.324)$.

A second post-treatment follow-up was conducted for $4 / 20$ of the initially enrolled patients (Table 5). These patients exhibited an initial response to rTMS treatment at 3 weeks; the mean VAS score decreased to $5.75 \pm 1.70$ $\mathrm{mm}$ from an initial $9.25 \pm 0.95 \mathrm{~mm}$ at baseline. At week 5 , the initial clinical improvement exhibited by our patients was sustained with a reported mean VAS score of $5.75 \pm 1.70 \mathrm{~mm}$.

\section{Discussion}

This study assessed the efficacy of high-frequency rTMS when applied for 5 successive days to 20 patients with

Table 2 Cohort comparisons for nerve conduction parameters

\begin{tabular}{|c|c|c|c|}
\hline Characteristic & Group A $(N=10)$ & Group B $(N=10)$ & $p$ \\
\hline \multicolumn{4}{|l|}{ Pre-treatment } \\
\hline Right ulnar sensory latency, mean (SD), ms & $3.68(0.39)$ & $3.27(0.76)$ & $0.049^{*}$ \\
\hline Right ulnar sensory conduction velocity, mean (SD), m/sec & $37.45(3.78)$ & $49.74(11.83)$ & $0.021^{*}$ \\
\hline Left ulnar sensory latency, mean (SD), ms & $3.36(0.27)$ & $3.04(0.20)$ & $0.046^{*}$ \\
\hline \multicolumn{4}{|l|}{ Post-treatment } \\
\hline Right ulnar sensory latency, mean (SD), ms & $3.30(0.49)$ & $3.22(0.84)$ & 0.429 \\
\hline Right ulnar sensory conduction velocity, mean (SD), m/sec & $42.32(7.37)$ & $49.49(10.06)$ & $0.046^{*}$ \\
\hline Left ulnar sensory latency, mean (SD), ms & $2.94(0.29)$ & $2.74(0.38)$ & 0.200 \\
\hline
\end{tabular}

*Significant $p$ value at $<0.05$

Group A insulin-dependent diabetics, Group B non-insulin-dependent diabetics, $p$ probability, SD standard deviation, $\mathrm{ms}$ milliseconds, $\mathrm{m} / \mathrm{sec} \mathrm{meter} / \mathrm{second}$ 
Table 3 Nerve conduction parameters prior to and following treatment

\begin{tabular}{|c|c|c|c|}
\hline Characteristic & Pre-treatment & Post-treatment & $p$ \\
\hline \multicolumn{4}{|l|}{ Insulin-dependent (group A) } \\
\hline \multicolumn{4}{|l|}{ Right tibial nerve, mean (SD) } \\
\hline Latency, ms & $4.98(1.57)$ & $4.54(1.20)$ & $0.035^{*}$ \\
\hline Conduction velocity, $\mathrm{m} / \mathrm{sec}$ & $37.49(5.81)$ & $42.71(4.56)$ & $0.005^{* *}$ \\
\hline \multicolumn{4}{|l|}{ Left tibial nerve, mean (SD) } \\
\hline Amplitude, mV & $3.69(2.33)$ & $4.41(2.25)$ & $0.007^{* *}$ \\
\hline Conduction velocity, $\mathrm{m} / \mathrm{sec}$ & $37.40(8.55)$ & $41.96(6.99)$ & $0.028^{*}$ \\
\hline \multicolumn{4}{|l|}{ Right peroneal, mean (SD) } \\
\hline Latency, ms & $4.77(1.05)$ & $4.48(1.10)$ & $0.028^{*}$ \\
\hline Conduction velocity, $\mathrm{m} / \mathrm{sec}$ & $37.96(5.66)$ & $41.90(4.55)$ & $0.008^{* *}$ \\
\hline \multicolumn{4}{|l|}{ Right motor ulnar nerve, mean (SD) } \\
\hline Conduction velocity, $\mathrm{m} / \mathrm{sec}$ & $51.11(5.15)$ & $54.10(4.72)$ & $0.005^{* *}$ \\
\hline \multicolumn{4}{|l|}{ Left motor ulnar nerve, mean (SD) } \\
\hline Latency, ms & $3.17(0.56)$ & $2.79(0.47)$ & $0.028^{*}$ \\
\hline \multicolumn{4}{|l|}{ Right sensory ulnar nerve, mean (SD) } \\
\hline Latency, ms & $3.68(0.39)$ & $3.30(0.49)$ & $0.012^{*}$ \\
\hline Conduction velocity, $\mathrm{m} / \mathrm{sec}$ & $37.45(3.78)$ & $42.32(7.37)$ & $0.012^{*}$ \\
\hline \multicolumn{4}{|l|}{ Left sensory ulnar nerve, mean (SD) } \\
\hline Latency, ms & $3.36(0.27)$ & $2.94(0.29)$ & $0.042^{*}$ \\
\hline Amplitude, $\mu \mathrm{V}$ & $7.16(4.83)$ & $11.58(6.22)$ & $0.043^{*}$ \\
\hline Conduction velocity, $\mathrm{m} / \mathrm{sec}$ & $42.26(6.34)$ & $47.24(11.81)$ & $0.043^{*}$ \\
\hline Upper limb F-wave latency, mean (SD), ms & $37.39(6.57)$ & $35.51(6.96)$ & $0.034^{*}$ \\
\hline Lower limb F-wave latency, mean (SD), ms & $57.34(6.95)$ & $54.34(7.17)$ & $0.043^{*}$ \\
\hline \multicolumn{4}{|l|}{ Non-insulin-dependent (group B) } \\
\hline \multicolumn{4}{|l|}{ Right tibial nerve, mean (SD) } \\
\hline Latency, ms & $5.93(2.98)$ & $5.22(2.08)$ & $0.02^{*}$ \\
\hline \multicolumn{4}{|l|}{ Left tibial nerve, (SD) } \\
\hline Conduction velocity, $\mathrm{m} / \mathrm{sec}$ & $38.96(5.28)$ & $42.23(6.37)$ & $0.005^{* *}$ \\
\hline \multicolumn{4}{|l|}{ Right peroneal nerve, mean (SD) } \\
\hline Conduction velocity, $\mathrm{m} / \mathrm{sec}$ & $40.77(4.83)$ & $42.49(3.72)$ & 0.074 \\
\hline \multicolumn{4}{|l|}{ Right ulnar (motor) nerve, mean (SD) } \\
\hline Latency, ms & $3.41(1.01)$ & $2.91(1.18)$ & $0.007^{* *}$ \\
\hline \multicolumn{4}{|l|}{ Left ulnar (motor) nerve, mean (SD) } \\
\hline Latency, ms & $3.56(1.08)$ & $3.04(1.10)$ & $0.007^{* *}$ \\
\hline Amplitude, mV & $5.21(3.60)$ & $5.93(3.21)$ & $0.047^{*}$ \\
\hline \multicolumn{4}{|l|}{ Left ulnar (sensory) nerve, mean (SD) } \\
\hline Latency, ms & $3.04(0.20)$ & $2.74(0.38)$ & $0.027^{*}$ \\
\hline Lower limb F-wave latency, mean (SD) & $53.89(6.73)$ & 51.84 (6.89) & $0.018^{*}$ \\
\hline
\end{tabular}

*Significant $p$ value at $<0.05$

**Highly significant $p$ value at $<0.01$

$p$ probability, $S D$ standard deviation, $m s$ milliseconds, $m / s e c$ meter/second, $\mu V$ microvolt, $m V$ millivolt 


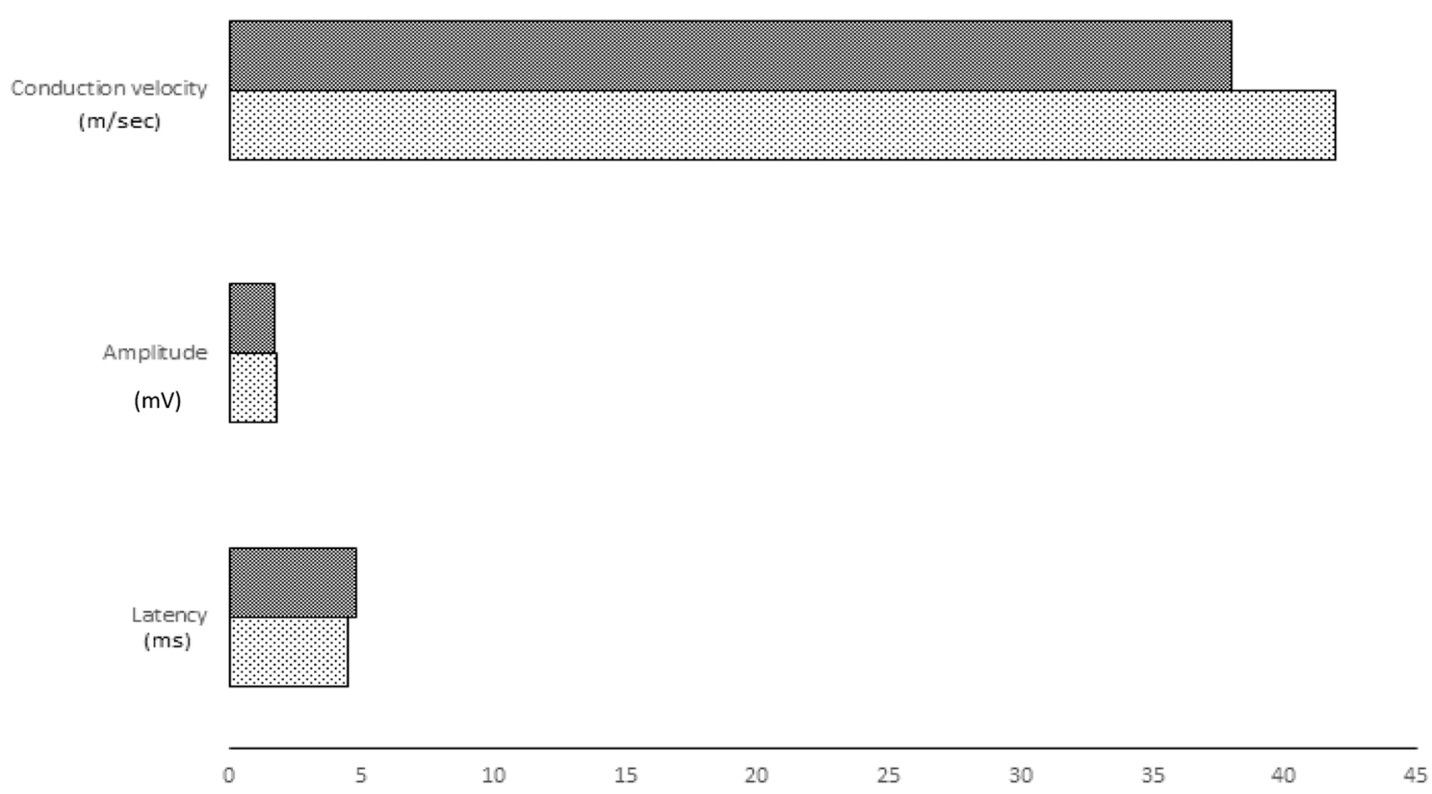

Right peroneal nerve
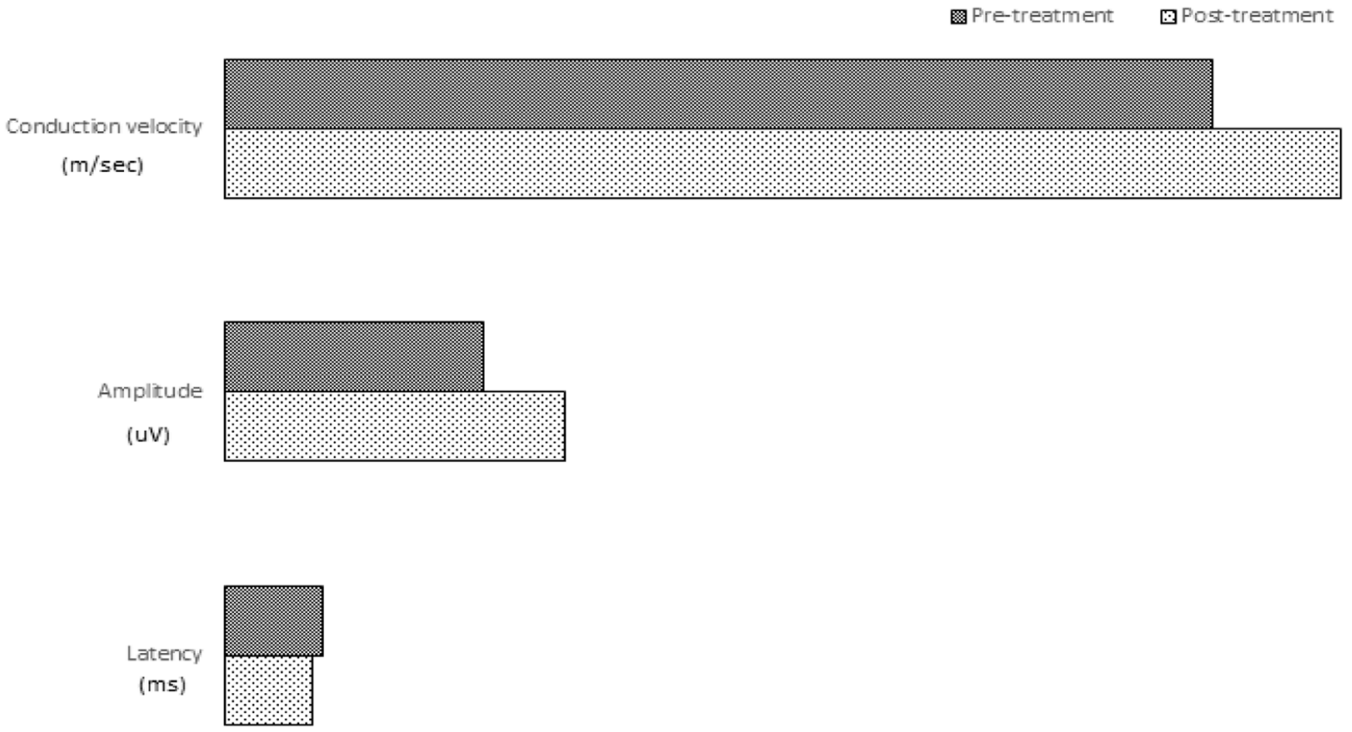

0

10

15

20

25

30

35

40

\section{Right ulnar sensory nerve}

Fig. 2 Change in nerve conduction following rTMS in the insulin-dependent cohort (group A) 
Table 4 Correlates of rTMS response

\begin{tabular}{llll}
\hline Variable & $R$ & $p$ & $N$ \\
\hline Age & 0.76 & 0.75 & 20 \\
Diabetes duration & -0.232 & 0.324 & 20 \\
\hline
\end{tabular}

$N$ number, $p$ probability, $R$ correlation coefficient

painful peripheral diabetic neuropathy. The major observations from our study included the following: (1) both insulin-dependent and non-insulin-dependent diabetics exhibited significant improvements in pain intensity following rTMS; (2) in patients participating in the observation for a long-term follow-up, the initial analgesic effect of rTMS was sustained 5 weeks following treatment; and (3) significant improvements in motor pathway outputs were observed following repeated motor cortex stimulation.

Based on their investigation, Farar and colleagues previously demonstrated that a 2 point or $30 \%$ reduction on a 0-10 pain numerical scale constitutes a clinically significant reduction of chronic pain [24]. In our current investigation, statistically and clinically significant reductions in subjectively rated pain were observed in insulin-dependent $(42.7 \%$ reduction; $p=0.011$ ) and non-insulin-dependent cohorts (51.2\% reduction; $p=0.005) 3$ weeks following rTMS. Our findings confirm observations by Onesti and colleagues who reported a similar reduction in pain 3 weeks following rTMS sessions to the lower limb motor cortex with an $\mathrm{H}$-shaped coil for five consecutive days [16]. Additionally, our observations are also in line with previous investigations demonstrating rTMS-induced reduction for various pain conditions including chronic intractable neuropathic pain, trigeminal neuralgia, post-stroke pain, spinal cord injury pain, fibromyalgia, and nerve root and peripheral nerve pain [25-30]. The reduction in pain for our patients is likely a consequence of an inhibition of pain processing pathways as a result of enhanced cortical plasticity. Repeated stimulation of the motor cortex can also induce activity changes in cortical and subcortical structures that are implicated in pain modulation, in addition to the thalamus, anterior cingulate, and insular cortices as previously demonstrated [12]. Furthermore, endogenous opioid secretions triggered by long-term motor cortex stimulation in synapses of inhibitory descending pathways can also be a mechanism involved in rTMS-induced analgesia of chronic neuropathic pain [31].

For patients in the longer-term observational follow-up, the effect of rTMS on VAS scores was sustained up to 5

Table 5 Observational 5-week follow-up $(n=4)$
\begin{tabular}{llll}
\hline Variable & Baseline & 3-week & 5-week \\
\hline VAS score, mean (SD) & $9.25(0.95)$ & $5.25(1.89)$ & $5.75(1.70)$ \\
\hline VAS visual analogue scale & &
\end{tabular}

weeks following treatment. Interestingly, our findings do not coincide with those made by Onesti and colleagues where the analgesic effect of rTMS at 3 weeks was no longer prevalent 5 weeks following treatment [16]. It should be noted that on the contrary, Onesti and colleagues administered repeat stimulation at $20 \mathrm{HZ}$ using an $\mathrm{H}$-coil.

To the best of our knowledge, this study was the first to investigate nerve conduction in patients with chronic painful diabetic neuropathy prior to and following rTMS. Significant improvements in nerve conductionparticularly for lower limb nerves-were observed at 3 weeks following repeated stimulation of the motor cortex. Our findings coincide with those by Belci and colleagues where improvements in motor and sensory functions were observed in patients with spinal cord injury following consecutive $10 \mathrm{~Hz}$ TMS, as well as observations by Pascual-Leone and colleagues (2002) who demonstrated long-lasting improvements in motor function following rTMS to the motor cortex [32, 33]. It is likely that repeat stimulation of the corticospinal pyramidal tract following rTMS results in increased spinal neuronal circuit plasticity and vascularity, thereby favorably impacting nerve conduction.

Treatment with rTMS was not associated with any adverse events in our patients, a finding that was consistent with previous reports [16, 26, 27, 30, 34]. Both Lee and colleagues and Picarelli and colleagues previously reported one incidence of seizure [35, 36]. However, it should be noted that these patients were subjected to higher frequency stimulation, and the estimated risk of inducing a single seizure with rTMS, based on the currently available data, is $<1 / 10,000$ [37].

In the current investigation, patients were subjected to once-daily TMS sessions repeated for five consecutive days. Whether patients stand to benefit from prolonged rTMS treatment remains an area of active debate. For instance, Lefaucheur and colleagues reported a durable 16-month pain relief following administered monthly sessions of rTMS [33]. In contrast, Topper and colleagues were unable to induce long-lasting pain reduction in two patients with daily $10 \mathrm{~Hz}$ rTMS stimulation for 3 weeks [38].

There is evidence to suggest that rTMS to other cortical regions-including the prefrontal cortex-may also induce analgesic effects. Graff-Guerrero and colleagues (2005) demonstrated increased cold presser tolerance following low-frequency $(1 \mathrm{~Hz})$ stimulation over the right prefrontal cortex [39]. Additionally, Borckardt and colleagues reported that 15-min TMS of the left prefrontal cortex can increase the thermal pain threshold [40]. Targeted stimulation of the cortical and subcortical regions of prefrontal cortex could increase mechanical and thermal thresholds in patients with painful and chronic neuropathies, potentially altering the perception of pain $[41,42]$. 
There are several limitations that should be noted when interpreting the findings from this current investigation. This study was initially designed to examine the feasibility of rTMS treatment in a diabetic cohort with painful neuropathy, and only a limited number of patients were recruited. While our preliminary results are very encouraging, the inclusion of a larger cohort of patients is required to more conclusively determine the analgesic effects of high-frequency rTMS. The lack of a control or sham arm makes it difficult to objectively ascertain the efficacy of rTMS for the management of chronic painful diabetic neuropathy. The stimulation was administered to our patients using a figure-of-eight coil. The use of an $\mathrm{H}$-coil however is more effective for stimulating lower limb nerves that are more difficult to reach.

\section{Conclusion}

Our current investigation was conducted to elucidate the potential therapeutic value of rTMS to manage painful peripheral neuropathy in diabetic patients. Our observations were consistent with previously conducted studies and indicate that high-frequency magnetic stimulation of the lower limb motor cortex can effectively reduce pain caused by chronic neuropathy in both insulinand non-insulin-dependent diabetics. Patients receiving this treatment also stand to benefit from improvements in nerve conduction. Additional investigations are required to elucidate the potential added benefit of administering higher frequency stimulation (e.g., $20 \mathrm{~Hz}$ ) to patients with peripheral neuropathies. Furthermore, additional investigations are also required to establish whether increasing the number of pulses or sessions is associated with consequent therapeutic benefits and to definitively determine the therapeutic value of rTMS to manage chronically painful neuropathies.

\section{Acknowledgements}

Not applicable

\section{Funding}

There is no source of funding for this research.

\section{Availability of data and materials}

All datasets generated and analyzed during the current study are not publicly available, but are available by reasonable request from the corresponding author.

\section{Authors' contributions \\ All authors contributed to the research idea. AAA, AME, and DAE contributed to the data collection. AME and DAE analyzed the data and along with AAA and HSM interpreted the data. Further, HSM completed the first draft of the article. All authors were involved in drafting the article or revising it critically for important intellectual content, and all authors approved the final version to be published.}

\section{Ethics approval and consent to participate}

All procedures performed in the study were in accordance with the ethical standards of the institutional research committee and with the 1964 Helsinki declaration and its later amendments. The study was ethically approved by the research committee and reviewed by the Faculty of Medicine of Cairo
University Board on 18 November 2013. Written informed consent was obtained from all participants involved in this investigation prior to the conduct of any study-related activities.

Consent for publication

Not applicable.

Competing interests

The authors declare that they have no competing interests.

\section{Publisher's Note}

Springer Nature remains neutral with regard to jurisdictional claims in published maps and institutional affiliations.

\section{Author details \\ ${ }^{1}$ Clinical Neurophysiology Unit, Cairo University, Cairo, Egypt. ${ }^{2}$ Department of Neurology, Kasr Al-Ainy Hospital, Cairo University, Cairo 12311, Egypt.}

Received: 20 November 2018 Accepted: 22 April 2019

Published online: 22 May 2019

References

1. World Health Organization. Global report on diabetes. Geneva: World Health Organization; 2016:1-88.

2. World Health Organization. Diabetes: Factsheet \# 312. 2015. https://www. who.int/en/news-room/fact-sheets/detail/diabetes. Accessed June 2017.

3. Wild S, Roglic G, Green A, Sicree R, King H. Global prevalence for diabetes. Estimates for the year 2000 and projections for 2030. Diabetes Care. 2004; 27(5):1047-53.

4. Karalliedde J, Gnudi L. Diabetes mellitus, a complex and heterogeneous disease, and the role of insulin resistance as a determinant of diabetic kidney disease. Nephrol Dial Transplant. 2016;31(2):206-13.

5. UK Prospective Diabetes Study (UKPDS) Group. Intensive blood-glucose control with sulphonylureas or insulin compared with conventional treatment and risk of complications in patients with type 2 diabetes (UKPDS 33). Lancet. 1998;352(9131):837-53.

6. Schreiber AK, Nones CF, Reis RC, Chichorro JG, Cunha JM. Diabetic neuropathic pain: physiopathology and treatment. World J Diabetes. 2015;6(3):432.

7. Tanenberg RJ, Donofrio PD. Neuropathic problems of lower limbs in diabetic patients. In: Bowker JH, Pfeifer MA, editors. The diabetic foot. $7^{\text {th }}$ ed. Philadelphia: Mosby Elsevier; 2008. p. 33-40.

8. Kim H, J Kim JJ, Yoon YS. Emerging therapy for diabetic neuropathy: cell therapy targeting vessels and nerves. Endocr Metab Immune Disord Drug Targets. 2012;12(2):168-78.

9. Attal N, Cruccu G, Baron RA, Haanpää M, Hansson P, Jensen TS, et al. EFNS guidelines on the pharmacological treatment of neuropathic pain: 2010 revision. Eur J Neurol. 2010;17(9):1113-e88.

10. Pop-Busui R, Boulton AJ, Feldman EL, Bril V, Freeman R, Malik RA, et al. Diabetic neuropathy: a position statement by the American Diabetes Association. Diabetes Care. 2017;40(1):136-54.

11. Cruccu G, Aziz TZ, Garcia-Larrea L, Hansson P, Jensen TS, Lefaucheur JP, et al. EFNS guidelines on neurostimulation therapy for neuropathic pain. Eur J Neurol. 2007;14(9):952-70.

12. Nguyen JP, Nizard J, Keravel Y, Lefaucheur JP. Invasive brain stimulation for the treatment of neuropathic pain. Nat Rev. 2011;7(12):699-709.

13. Klein MM, Treister R, Raij T, Pascual-Leone A, Park L, Nurmikko T, et al. Transcranial magnetic stimulation of the brain: guidelines for pain treatment research. Pain. 2015 Sep 1;156(9):1601-14.

14. Koch G, Franca M, Mochizuki H, Marconi B, Caltagirone C, Rothwell JC. Interactions between pairs of transcranial magnetic stimuli over the human left dorsal premotor cortex differ from those seen in primary motor cortex. J Physiol. 2007 Jan 15;578(2):551-62.

15. Krings $T$, Buchbinder BR, Butler WE, Chiappa $K H$, Jiang $H J$, Rosen $B R$, et al. Stereotactic transcranial magnetic stimulation: correlation with direct electrical cortical stimulation. Neurosurgery. 1997 Dec 1;41(6):1319-26.

16. Onesti E, Gabriele M, Cambieri C, Ceccanti M, Raccah R, Di Stefano G, et al. $\mathrm{H}$-coil repetitive transcranial magnetic stimulation for pain relief in patients with diabetic neuropathy. Eur J Pain. 2013 Oct 1;17(9):1347-56.

17. England JD, Gronseth GS, Franklin G, Miller RG, Asbury AK, Carter GT, et al. Distal symmetrical polyneuropathy: a definition for clinical research. A report 
of the American Academy of Neurology, the American Association of Electrodiagnostic Medicine, and the American Academy of Physical Medicine and Rehabilitation. Arch Phys Med Rehabil. 2005 Jan 31;86(1):167-74.

18. Bouhassira D, Attal N, Fermanian J, Alchaar H, Gautron M, Masquelier E, et al. Development and validation of the neuropathic pain symptom inventory. Pain. 2004 Apr 30;108(3):248-57.

19. Perez C, Galvez R, Huelbes S, Insausti J, Bouhassira D, Diaz S, et al. Validity and reliability of the Spanish version of the DN4 (Douleur Neuropathique 4 questions) questionnaire for differential diagnosis of pain syndromes associated to a neuropathic or somatic component. Health Qual Life Outcomes. 2007; Dec 4;5(1):66.

20. Huskisson EC. Measurement of pain. Lancet. 1974 Nov 9;304(7889):1127-31.

21. Ho K, Spence J, Murphy MF. Review of pain-measurement tools. Ann Emerg Med. 1996 Apr 30;27(4):427-32.

22. Tankisi H, Pugdahl K, Fuglsang-Frederiksen A, Johnsen B, de Carvalho M, Fawcett PR, et al. Pathophysiology inferred from electrodiagnostic nerve tests and classification of polyneuropathies. Suggested guidelines. Clin Neurophysiol. 2005 Jul 31;116(7):1571-80.

23. Chan YH. Biostatistics 102: quantitative data-parametric \& non-parametric tests. Singap Med J 2003; 140(24.08):79-00.

24. Farrar JT, Young JP, LaMoreaux L, Werth JL, Poole RM. Clinical importance of changes in chronic pain intensity measured on an 11-point numerical pain rating scale. Pain. 2001:94(2):149-58.

25. Khedr EM, Kotb H, Kamel NF, Ahmed MA, Sadek R, Rothwell JC. Longlasting antalgic effects of daily sessions of repetitive transcranial magnetic stimulation in central and peripheral neuropathic pain. J Neurol Neurosurg Psychiatry. 2005 Jun 1;76(6):833-8.

26. Andre-Obadia N, Peyron R, Mertens P, Mauguiere F, Laurent B, Garcia-Larrea L. Transcranial magnetic stimulation for pain control. Double-blind study of different frequencies against placebo, and correlation with motor cortex stimulation efficacy. Clin Neurophysiol. 2006;117:1536-44.

27. Hirayama A, Saitoh Y, Kishima H, Shimokawa T, Oshino S, Hirata M, et al. Reduction of intractable deafferentation pain by navigation-guided repetitive transcranial magnetic stimulation of the primary motor cortex. Pain. 2006 May 31;122(1):22-7.

28. Lefaucheur JP. New insights into the therapeutic potential of noninvasive transcranial cortical stimulation in chronic neuropathic pain. Pain. 2006 May 1;122(1):11-3.

29. Lefaucheur JP, Antal A, Ahdab R, de Andrade DC, Fregni F, Khedr EM, et al. The use of repetitive transcranial magnetic stimulation (rTMS) and transcranial direct current stimulation (tDCS) to relieve pain. Brain Stimul. 2008:1 (4):337-44.

30. Saitoh Y, Hirayama A, Kishima H, Shimokawa T, Oshino S, Hirata M, et al. Reduction of intractable deafferentation pain due to spinal cord or peripheral lesion by high-frequency repetitive transcranial magnetic stimulation of the primary motor cortex. J Neurosurg. 2007 Sep;107(3):555-9.

31. Belci M, Catley M, Husain M, Frankel HL, Davey NJ. Magnetic brain stimulation can improve clinical outcome in incomplete spinal cord injured patients. Spinal Cord. 2004 Jul 1:42(7):417-9.

32. Pascual-Leone A, Manoach DS, Birnbaum R, Goff DC. Motor cortical excitability in schizophrenia. Biol Psychiatry. 2002;52(1):24-31.

33. Lefaucheur JP, Drouot X, Menard-Lefaucheur I, Zerah F, Bendib B, Cesaro P, Keravel Y, Nguyen JP. Neurogenic pain relief by repetitive transcranial magnetic cortical stimulation depends on the origin and the site of pain. J Neurol Neurosurg Psychiatry. 2004 Apr 1;75(4):612-6.

34. O'Connell NE, Wand BM, Marston L, Spencer S, Desouza LH. Non-invasive brain stimulation techniques for chronic pain. Cochrane Database Syst Rev. 2014:4:CD003208.

35. Lee SJ, Kim DY, Chun MH, Kim YG. The effect of repetitive transcranial magnetic stimulation on fibromyalgia: a randomized sham-controlled trial with 1-mo follow-up. Am J Phys Med Rehabil. 2012 Dec 1;91(12):1077-85.

36. Picarelli H, Teixeira MJ, de Andrade DC, Myczkowski ML, Luvisotto TB, Yeng $L T$, et al. Repetitive transcranial magnetic stimulation is efficacious as an add-on to pharmacological therapy in complex regional pain syndrome (CRPS) type I. J Pain. 2010 Nov 30;11(11):1203-10.

37. Rossi S, Hallett M, Rossini PM, Pascual-Leone A, Safety of TMS Consensus Group. Safety, ethical considerations, and application guidelines for the use of transcranial magnetic stimulation in clinical practice and research. Clin Neurophysiol 2009; 120(12):2008-2039.
38. Töpper R, Foltys H, Meister IG, Sparing R, Boroojerdi B. Repetitive transcranial magnetic stimulation of the parietal cortex transiently ameliorates phantom limb pain-like syndrome. Clin Neurophysiol. 2003 Aug 31;114(8):1521-30.

39. Graff-Guerrero A, González-Olvera J, Fresán A, Gómez-Martín D, MéndezNúnez JC, Pellicer F. Repetitive transcranial magnetic stimulation of dorsolateral prefrontal cortex increases tolerance to human experimental pain. Brain Res Cogn Brain Res. 2005;25(1):153-60.

40. Borckardt JJ, Smith AR, Reeves ST, Weinstein M, Kozel FA, Nahas Z, et al. Fifteen minutes of left prefrontal repetitive transcranial magnetic stimulation acutely increases thermal pain thresholds in healthy adults. Pain Res Manag. 2007;12(4):287-90.

41. Lorenz J, Minoshima S, Casey KL. Keeping pain out of mind: the role of the dorsolateral prefrontal cortex in pain modulation. Brain. 2003 May 1;126(5):1079-91.

42. Borckardt JJ, Reeves ST, Frohman H, Madan A, Jensen MP, Patterson D, et al. Fast left prefrontal rTMS acutely suppresses analgesic effects of perceived controllability on the emotional component of pain experience. Pain. 2011 Jan 31;152(1):182-7.

\section{Submit your manuscript to a SpringerOpen ${ }^{\circ}$ journal and benefit from:}

- Convenient online submission

- Rigorous peer review

- Open access: articles freely available online

- High visibility within the field

- Retaining the copyright to your article

Submit your next manuscript at $\boldsymbol{\nabla}$ springeropen.com 